\title{
Relational Leadership IN DESIGN ProJeCtS
}

\author{
Claudia Bennett and Minha R. Ha \\ York University \\ minhareo@yorku.ca,
}

\begin{abstract}
As a continuation of previous research pertaining to the self-assessed effectiveness in various interpersonal aspects by undergraduate Mechanical Engineering students as the Lassonde School of Engineering, the authors present in this paper, the findings of new research elaborating upon areas of concern surmised from the prior study. Motivation for this new research stems from the previous data relating to interpersonal and team relational skills inadequacies and the experiences of this paper, the authors present the findings of new research continue upon previous research pertaining to undergraduate students in Mechanical Engineering program self-assessment of effectiveness. The main objective of this paper is to present upon the common challenges of design team projects according to students, and the influence (or relation) effective and/or ineffective interpersonal relationship skills have upon those challenges. Results from this investigation indicates that human-related challenges experienced in team projects stem largely from ineffective manipulation of communication and relational skills and the various facets of team dynamics directly and indirectly affected by them. Additionally, research indicated that females team members had more gendered experiences with their teams. The author found there to be correlations between the negative female experiences and ineffective relational / interpersonal skills.
\end{abstract}

Keywords: Teamwork, design project, relational leadership

\section{INTRODUCTION}

Mechanical Engineering curriculum at Lassonde places a strong emphasis on learning engineering design, which is mostly taught in team project settings [1]. The presence of diverse perspectives and backgrounds of team members has been shown to positively impact student learning [1-2]. Given the assumption that team diversity contributes to higher quality in design, it merits attention to study how students might activate the creative potential of the 'collective genius' [4] - in other words, the collaboration of many out-performs compilation of isolated, individual efforts.

Unfortunately, it remains unclear how students might best learn to overcome the all-too persistent issues with teamwork, such as uneven contributions and conflicts, with underlying complexities of social relations and institutional culture [2], [3]. The structural factors, such as gender, become influential parts of our institutional culture through historically-established practices, benefiting some and disadvantaging others namely those perceived as less valuable to the team. Team relations within project teams can create or reflect school culture [2], and it is in this dynamic that the effects of background factors would be experienced firsthand either to the benefit or detriment of effective teamwork.

This paper draws from a larger study that aims to bring in-depth knowledge of localized processes of learning and development; therefore, the data are largely qualitative and the study design is exploratory. This paper focuses on the comparison and contrast of perspectives on team relations given female and male mechanical engineering students. Presently, the femaleto-male ratio in Mechanical Engineering remains very small; however, the department is part of a school that is making explicit efforts to attract more women into the field of engineering. In 2015, the Lassonde School of Engineering at York University made public the 'Lassonde 50:50 Challenge', a \$1.5 million challenge to align their efforts to be the first engineering school in Canada to achieve a 50:50 gender balance. The challenge is a large undertaking that begs many question why the field has not already reach parity as of today and what the experience is like for the minority of females presently engaged in the field. As the pilot study on design engineering education, in mechanical engineering grew, we were able to obtain data to investigate gender differences in student experience and perspectives. We believe it is especially important to bring out the marginalized voices of female students on the gendered experiences within engineering education.

Our investigation exploring the student experience of design team projects experiences began with surveys administered to students en masse for large robust data 
on the overall experience in design engineering program, from their experiences in team work, comprehension of curriculum concepts, interaction with teaching staff and relatability to engineering field as they perceive it. In order to obtain qualitative data exploring the male and female experiences, multiple focus groups interviews were conducted. The working hypothesis for focus group interviews was to discuss whether design teams, working with female students had notable differences to the way in they applied or modified their relational leaderships skills, as well as the perceived effectiveness of their usage of these skills for success in projects. This hypothesis was developed from analysis the survey responses that were collected. The following questions were the basis around which the interviews were conducted in order to gather sufficient understanding of perceived causal relationships of challenges and success and any other correlating factors:

The questions addressed in this paper are as follows:

(1) What are the experienced challenges in team relations? How do they impact design project outcomes? How do students deal with the interpersonal challenges?

(2) What principles do students emphasize for effective team relations?

(3) How do background characteristics influence or characterize the interpersonal challenges and strategies?

In order to characterize students' approaches to dealing with teamwork challenges, we adopt Komives, Lucas and McMahon's [5] Relational Leadership Model (RLM) that was based on their extensive work with college students. They define leadership as that which happens among people engaged in change. Since learning is a process of change, and this paper focuses on the relational experiences within design teams, this model appropriately offers a useful set of concepts to identify sets of knowledge, attitude, and skills that practically express relational principles (purposeful, inclusive, empowering, ethical, and process-oriented).

The results of this analysis have the potential to contribute to the following: (i) inform curriculum/course designers to facilitate or establish effective team-building or communication standards that also respects the diversity among students; (ii) help faculty reflect on their own influence on the students' peer relations, including gender relations, and become sensitive and aware in their actions and reactions in the classroom; (iii) enable faculty to prepare students and teaching assistants with the language and framework to articulate, address, and critique issues of discrimination or marginalization; and (iv) help project supervisors identify problems in design teams early and advise students with more adaptive, respectful, and effective strategies of teamwork. We welcome discussions from our colleagues in this regard.

\section{METHODOLOGY}

\subsection{Data Collection}

Participants in this study are undergraduate students in the Mechanical Engineering program at Lassonde School of Engineering, York University. Data for this paper are drawn from a larger, longitudinal study on design education in engineering.

Researchers visited classes and approached design clubs to recruit participants. The first set of in-depth interviews were conducted with 3 male students in Winter 2016. Follow-up interviews were conducted in Winter and Summer 2016. The only female interview participants (2 in total) in the larger study were interviewed in Winter 2017, including follow-up interviews. Interviews were transcribed verbatim.

Anonymous surveys to both second and third-year students were administered in Winter 2017. Students had the option to participate online or on paper. In total, 21 third-year students $(86 \%$ male, $9 \%$ female, $5 \%$ unspecified) and 73 second-year students (80\% male, $11 \%$ female, $9 \%$ unspecified) participated.

Two types of data were retrieved from the larger survey database. The first set of responses (open-ended) addressed the students' self-recognized changes in their approach to working with people (comparing first year to upper year). The second set of responses (rating) pertained to the students' self-assessment of their effectiveness in various skills relating to teamwork.

\subsection{Data Analysis}

Interview data were reviewed by two researchers. First, participants' descriptions and explanations of interpersonal challenges (experienced during design projects) and response strategies (to solve the interpersonal challenges) were identified. The types of challenges and response strategies were characterized, and then linked to particular effects on the design project outcome. Secondly, constructions of background characteristics (e.g. male-female, young-mature) were analyzed, from the way participants used such characteristics to explain behaviours and abilities that relate to team challenges.

Open-ended responses from surveys were first reviewed by the lead researcher (Ha) to develop thematic categories. A research assistant applied the developed coding scheme to label all open-ended responses, and generated frequency counts in each category. Sub- 
categories were generated upon a third review of the data, to clarify categories and check the results of coding.

\section{RESULTS AND DISCUSSION}

\subsection{Female Student Experience}

3.1.1 Teamwork Issues. The far reach of communication into the varying aspects of team dynamics was a major component in the female student experience. When effective, communication and the relational team attributes it affects could benefit at least one area if not more of team project aspects (ie. Team trust and cohesiveness, design project success, project and team management). Examples of barriers exacerbated by poor communication are as follows: ineffective conveyance of ideas led to incidences throughout the course of projects of (i) misunderstandings - which tasks were assigned to whom (S5) "we weren't listening to each other... this person was supposed to do this, but instead did this...leading to resentment and double work", (ii) misinterpretations lacking opportunity for follow-up discussion, written peer feedback were easily misinterpreted or less helpful without full comprehension of what was written. (iii) lack of communication - projects commenced without thorough planning and organization inefficient use of team and risking time constraints. (S5) "When we communicate it will often be unresolved, in the sense, I feel like we have to stop talking about this to avoid conflict, not because we actually reached a solution or common ground or collaborative going forward.". Inclusivity was strongly influenced by the manner team members approached team work. Gendered language and assumptions by male counterparts were noted by female students not uncommon and strongly exclusionary and to female team members. This came in the form of (i) female student ideas being brushed aside and not being considered/testing as viable options during projects, (ii) constant competitive nature as opposed to supportive team membership from males (iii) gendered jokes and assumptions of female student capabilities to participates in various parts of design projects. These gender dividing actions created feelings of discomfort, exclusion and demotion of empowerment among female students. Another common issue with purpose and commitment to projects and tasks. Commitment to projects and task can vary for each member for a multitude of reasons (i) familial responsibilities (ii) lack of interest in the course/project (iii) different value placed on the content and impact of assignment (iv) different standards of quality. When the priorities of members are skewed, many of the previous mentioned issues can arise causing member conflict to arise.

The students noted grave impact on their design project processes when any combination of the above issues arose. Communication malfunctions were strongly correlated to the inundation of workload on certain members due to misinterpretations, poorly communicated or agreed upon standards of quality, preconceived ideals of female student abilities and willingness to engage, as well as lack of commitment by members during project. The impact were high stress points during projects as well as after project terminations.

Strategies to prevent and resolve variety of team issues that arose throughout the course of projects attempted by students and resulted in varying impacts on the team and design projects. Females students noted that many of the issues were or could have been resolved with correct application of varying combinations of relational leadership principals.

Example of poor communication and monopolization of work / exclusion of members impacting team cohesion and project success: S5 "We had one member that was kind of, not as outspoken, but had some very good, like useful feedback for what we had chosen but hadn't spoken up about it. I later talked to him about it and we came to a good moment of access.... That was a conversation that we hadn't had but we should have had sooner... We had somebody else that was very good at building things and carrying things out, and he kind of monopolized that part. And this person I found very difficult to communicate with, on both of our parts. I feel like our project could have done infinitely better... Our $2^{\text {nd }}$, actual final design did worse than our original prototype...he didn't account for, because one person can't account for everything. In that scenario, there were things that I knew I could have fixed, if I was given the chance to be a part of the process, which was a little bit frustration, because, I felt like at the point, everybody wasn't contributing."

\subsubsection{Emphasized Principles in Effective Team}

Relations. Inclusivity and its associated competencies were most empathized by female students as the means to creating and supporting an effective environment for positive team relations. They highlighted the inclusive competencies: talent development - sharing the workload, peer teaching not doing; listening skills engaging and allowing all team members to contribute; facilitation- honest and effective communication throughout; consultation - compromise and consensus in decision making; relationship building - respect of team, and self accountability to develop trust. Additionally, noted principles: Ethical - self and others' value, value 
integrity, being congruent - efficacy and transparency in communication; process oriented - process is as important as the outcome, standards of quality, management adaptation; empowerment - control is not possible, value others contribution, willingness to share power and foster peer learning and teaching.

Unnecessary mean stigma that engineers conjured up like your, mental health can be deteriorating but you're in engineering so suck it up...we seem to be very focused on success and doing better than everyone and I'm not for that...engineering is a very people oriented field you need to care for the people because everything you're doing is about them so the whole idea of being selfish and self-obsessed is unnecessary..." (Student 4)

3.1.3 Construction of Gender. Females students reported being treated by cohort peers in gendered presuming manners. This includes incidences of peers overtaking work tasks in assumption of female students' inability or lack of desire to partake. During the course of design projects, females' students also noted that many of their communicative efforts to assuage or resolve conflicts and issues were perceived by male counterparts as not a serious attempt or a negative confrontation in lieu of being opportunities for team member discussion, clarification and expression of ideas and/or concerns. Attempts to challenges these preconceived norms were often met with humor to diffuse and end the discord or with frustration at the female as she did not come off as "prioritizing getting things done versus just sitting and talking about this or that." (S4).

"You have to approach them [team members] with the right mindset... A lot of people view communicating as a very fluffy and unnecessary thing, but it reaches a point where I can't have a conversation with you because you don't think you need to have it." (S5) “...the projects that went well with communication, we worked better together, better distribution of work, everyone was more satisfied and more of their potential." (S5)

Students noted that interactions and team project with other females were less conflicting (S4) "I've yet to meet a female engineering student that holds competition to the same unnecessary level that males do in our classes and never tear each other down which in nice... I notice that there seems to be cliques in engineering with males and females... the groups that have females in them tend to be a little more open, are a lot nicer."

These experiences in the classroom fostered by norms of the cohort and fields are problematic in the promotion of continued marginalization of the existing female population at mechanical engineering and could have devastating effects on potential future females' students considering entering the field. Gendered language, assumptions and practices are prohibitive to females trying to fully engage in the full spectrum of engineering education as they became disengaged and frustrated with the process of participation with the expectation and mental preparation of such exclusionary behaviors.

\subsection{Male Student Experience}

3.2.1 Teamwork Issues. Some of the issues that the male students experienced in teamwork were: unequal commitment levels; conflict avoidance; unequal skilllevels in contributing to the computer-aided design or final product development; misaligned priorities and expectations of quality; barriers to negotiating a common goal; and lack of effective decision-making process. These issues commonly led to an uneven workload, frustration among group members, and lack of opportunity to critical evaluate and improve design outcomes.

Students employed various strategies to address the issues. The biggest issue, unequal commitment level, is taken up as an example. For motivating a disengaged or underperforming member, students most often took the conversational approach to influencing a peer's behavior and perspective. As well, students developed project activities or discussions that helped each member connect meaningfully to the project.

To find their own strengths and give them that responsibility. So things that they're interested in, and that they excel in, then they'll find more commitment and they'll want to be part of it more... That way they're doing something more for themselves, and they want it, they're motivated to complete it and to do well in it. And I guess to keep, to have a friendly environment that it's not something hostile that they don't want to do something. (Student 2)

Ask group members first, what they actually want to do, instead of just saying 'you're going to do this, you're going to do that'. Beforehand, just ask them what they're interested in and what they're actually good at and what they want to do. And then, designating tasks gets more easy, and if they actually want to do the work they're assigned and they'll work better and the whole group as a whole works better. (Student 1)

Tasks should connect meaningfully to students' interests and skillsets. The team environment should create a positive environment that enables the best from each member. It is important to respect the peers' sense of autonomy and their personal meaning to the project. 
[One new member] didn't really seem to participate... We figure out it might be because we are all friends [except the new member]... We were asking if [s/he] has any ideas or if [s/he] wanted to contribute any other ways... make sure everyone... gives feedback on the group and how they we are working as a team... the main thing [is] voicing your concern to them. Because sometimes they won't even know they're not doing it cause some people like to take charge of it and do all the work themselves. But then you can't backlash at the other person for not doing work [when you decided to] do it all yourself... And then if it doesn't get resolved through you meeting with the group... I think you'd have to include the instructor... (Student 3)

All students challenged the assumption that the uncontributing member is necessarily unmotivated or deliberately refusing to work. Some students feel the tasks are ill-fit with their interests or abilities. Other students may feel left out from having an influence on the project decisions. Being part of the design tasks is more than just sharing work - It involve learning, as well as a sense of membership and belonging.

While students spoke highly of intrinsic motivation to work hard and seek quality in their project work, they also recognized the impact of sheer workload and the grading system (weight distribution, schedule of deliverables) on pushing students towards pursuing the 'minimum required':

(What keeps your motivation?) I guess just being goal driven and knowing that I'm in school to learn... to succeed and do my best and get the best grades I can... [For some others,] they don't have to be committed so much to... as project, as long as they're getting a certain grade... everyone's busy with school, so they're putting in the time for things that matter the most maybe... [between a test and] a certain part of a team project, they might not choose [the] team project. (Student 2)

3.2.2 Emphasized Principles in Effective Team Relations. Inclusivity, transparency, fairness, collaboration, commitment, purpose, empowerment these were among many principles of effective team relations that were identified by students. For example, Student 2 describes a particular peer who was chosen as a good team leader:

He's organized, confident in his decisions... everyone just trusted that he would be the best person for the job... aside from delegating the different tasks, he also checked in with each member to see how they were doing and to help out... he was very interested in the project, so he wanted to do the best he could and he wanted other people to do the best. So he made sure that people were [focused]... When you have multiple people working together with different strengths and weaknesses and being able to put all your ideas together and it's really useful. (Student 2)

3.2.3 Peer Knowledge as Important Factor. Gender did not emerge as an important theme in the male students' discussion of problems in teamwork and team relations. However, Student 2 mentioned that "the students are getting closer together and everyone is helping each other... In first year, there wasn't so much collaboration... now... you know each person's name... you know how they work and you can work with them better." Student 3 also mentioned in a separate session, "we've [been] able to just teach each other, where everyone struggles and where we can contribute best to the group."

\subsection{Survey Responses}

Four themes emerged from the open-ended responses to the question item, 'Compare yourself now to the start of the program. What are the biggest changes in the way you work with and relate to people?' (Sections 3.3.13.3.3). They are described with examples below.

3.3.1 Value of Teamwork. Students recognized the value of teamwork as a result of their program experience. At the same time, some students recognized that ineffective teamwork has a negative impact on learning, and thus more selective in team formation (Table 1). The mixed experiences suggest that the existence of a project group does not guarantee effective team relations nor project success.

Table 1: Sample Responses, Value of Teamwork.

\begin{tabular}{|l|l|l|}
\hline $\begin{array}{l}\text { Particip. } \\
\text { ID }\end{array}$ & First Year & Second Year \\
\hline L2S7 & $\begin{array}{l}\text { wasn't sure how much } \\
\text { quality of work }\end{array}$ & $\begin{array}{l}\text { realize doing a } \\
\text { group project } \\
\text { alone is too much } \\
\text { and must trust } \\
\text { group members }\end{array}$ \\
\hline L2S27 & individualistic & $\begin{array}{l}\text { more open \& } \\
\text { cooperating in } \\
\text { collaborating with } \\
\text { other people }\end{array}$ \\
\hline L2O34 & $\begin{array}{l}\text { I was very open to } \\
\text { working in group } \\
\text { settings with other }\end{array}$ & $\begin{array}{l}\text { I nore reluctant to } \\
\text { mom I work with } \\
\text { whom I }\end{array}$ \\
\hline
\end{tabular}




\begin{tabular}{|l|l|l|}
\hline engineering students & $\begin{array}{l}\text { in group projects } \\
\text { due to the various } \\
\text { turn out. }\end{array}$ \\
\hline
\end{tabular}

Interview participants confirm and elaborate on the value of teamwork, and the risks of teamwork. For example, Student 2 commented: "One thing I love about teams, is that when everyone has different abilities and different strengths and you all put in... put it together and you make one great compilation of everything that's good." On the other hand, Student 1 explained: "Team management... it's more time consuming... If there's a dispute and half your team splits, you cannot move forward with the whole project... keeping track if everyone is on board with one idea, it's really important... the project manager, he plays a a really important role overall. Working with a lot of people, gets a bit difficult sometimes." $\square$

3.3.2 Required Strategies for Effective Teamwork. Students identified practical strategies of teamwork as notable learning outcomes. Such strategies included structuring and facilitating team activities, utilizing people's strengths, and creating a team environment (i.e. trust) that enables the best out of all team members (Table 2). RLM Principles of inclusivity, processorientation and empowerment are most notable in this theme. These principles are echoed by interview data:

One thing that's important... that everyone is on the same page and... agreeing to what you're doing and you have everyone's opinion on it and you kind of figure out a way where everyone is involved. Sometimes for team meetings, or brainstorming... you want everyone to be present and to be part of it... [With] a proper procedure to go about, there's more understanding [developed] between people. Like 'right now we're going to do this, and after we're going to do this'. The whole time they're prepared for the process and they know what they're going to be doing in the future and what they're doing right now. So... [it] helps them work effectively. (Student 2)

Table 2: Sample Responses, Teamwork Strategies.

\begin{tabular}{|l|l|l|}
\hline $\begin{array}{l}\text { Particip. } \\
\text { ID }\end{array}$ & First Year & Second Year \\
\hline L2O4 & $\begin{array}{l}\text { I was anxious as I I feel a bit more } \\
\text { didn't feel confident }\end{array}$ & $\begin{array}{l}\text { confident about } \\
\text { group work as long }\end{array}$ \\
& $\begin{array}{l}\text { working in a team } \\
\text { dynamic and having } \\
\text { a large portion of } \\
\text { grades dependent on }\end{array}$ & $\begin{array}{l}\text { as there are set } \\
\text { meetings progress }\end{array}$ \\
\hline
\end{tabular}

\begin{tabular}{|l|l|l|}
\hline & the work of others. & $\begin{array}{l}\text { can be made steadily } \\
\text { and efficiently. }\end{array}$ \\
\hline L2O17 & $\begin{array}{l}\text { I had some trouble } \\
\text { working with people } \\
\text { who have different } \\
\text { styles and methods. }\end{array}$ & $\begin{array}{l}\text { I'm trying to learn to } \\
\text { manage my groups } \\
\text { and find ways to use } \\
\text { each person's skills } \\
\text { to their full extent. }\end{array}$ \\
\hline $\begin{array}{l}\text { Particip. } \\
\text { ID }\end{array}$ & $\begin{array}{l}\text { First Year } \\
\text { L3O6 } \\
\text { people who do not } \\
\text { show up to the } \\
\text { presentation and do } \\
\text { zero work }\end{array}$ & $\begin{array}{l}\text { I work specifically } \\
\text { with the people I } \\
\text { trust so that I may } \\
\text { actually give my best } \\
\text { work }\end{array}$ \\
\hline
\end{tabular}

3.3.3 Leadership and Positive Influence on Teams. Students also grew in their ability to influence and lead their project teams. Students identified evidence of their demonstrated leadership abilities in the way they confront areas needing change, taking the initiative to lead team processes, and assuming leadership roles (Table 3). These themes resonate with the RLM principles of being ethical, purposeful.

Table 3: Sample Responses, Leadership.

\begin{tabular}{|c|c|c|}
\hline $\begin{array}{l}\text { Particip. } \\
\text { ID }\end{array}$ & First Year & Second Year \\
\hline L2O9 & $\begin{array}{l}\text { Being comfortable } \\
\text { with my teammates } \\
\text { and talking to them } \\
\text { well. }\end{array}$ & $\begin{array}{l}\text { Being comfortable } \\
\text { speaking out against } \\
\text { inappropriate } \\
\text { behavior }\end{array}$ \\
\hline L2O29 & $\begin{array}{l}\text { Only sometimes } \\
\text { contributed to the } \\
\text { conversation }\end{array}$ & $\begin{array}{lr}\text { Usually } & \text { initiates } \\
\text { conversation } & \text { and } \\
\text { contribute } & \text { to } \\
\text { discussions } & \\
\end{array}$ \\
\hline $\begin{array}{l}\text { Particip. } \\
\text { ID }\end{array}$ & First Year & Third Year \\
\hline L3O1 & $\begin{array}{ll}\text { Not good with } \\
\text { conducting } \\
\text { tasks }\end{array}$ & $\begin{array}{l}\text { Takes leadership } \\
\text { roles when required, } \\
\text { tries to use people's } \\
\text { strengths to work } \\
\text { together }\end{array}$ \\
\hline L3S6 & $\begin{array}{l}\text { I used to stay away } \\
\text { from the leadership } \\
\text { positions }\end{array}$ & $\begin{array}{l}\text { I take initiative and I } \\
\text { am appointed leader } \\
\text { most of the time }\end{array}$ \\
\hline
\end{tabular}

Student 2 also adds insights to having a positive influence on other students: "Sometimes I get taken advantage of a little bit... I can't just give other people the answers and how to do things. But it's something that I can teach them or help them start learning". 


\subsubsection{Self-assessment of Effectiveness in RLM Principles.}

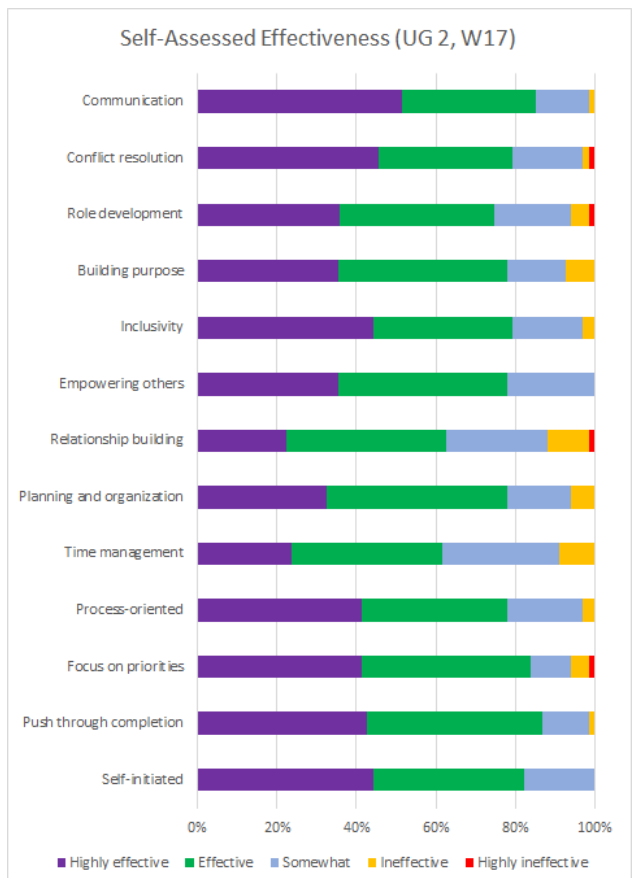

Students varied greatly from the second to third year cohorts in certain aspects of their self-assessed effectiveness in RLM principles. It is noteworthy that the $3^{\text {rd }}$ year cohort has $\ldots$ females-female students and the $2^{\text {nd }}$ year cohort has __ females. In analyzing the $2^{\text {nd }}$ year cohort data, their two highest competencies are (i) communication and (ii) inclusivity. Considering the higher concentration of female students in the $2^{\text {nd }}$ year cohort, inclusivity is quite possibly naturally assumed when looking at the configurations of teams. The two lowest self-assessed competencies for the $2^{\text {nd }}$ year cohort are (i) time management and (ii) relationship building. Time management was a prominent discussion from both males and female students regarding the difficulty in balancing multiple simultaneous group projects in their courses along with the rest of their academic, extracurricular and personal responsibilities. It must be noted that lowest self-assessed effective competencies of the $2^{\text {nd }}$ year cohort, which is relationship building, is contradictory to that which they self-assessed to be their second most effective competency, inclusivity. Part of Inclusivity according to the RLM set for by Komives (2007) shows that the principle of Inclusivity is fosters by the skill of relationship building. Considering the feedback by $2^{\text {nd }}$ year females students pertaining to their experiences of peers' exclusionary behaviors, it is justifiable to look further into reasoning and justification for the male student perception of inclusivity.

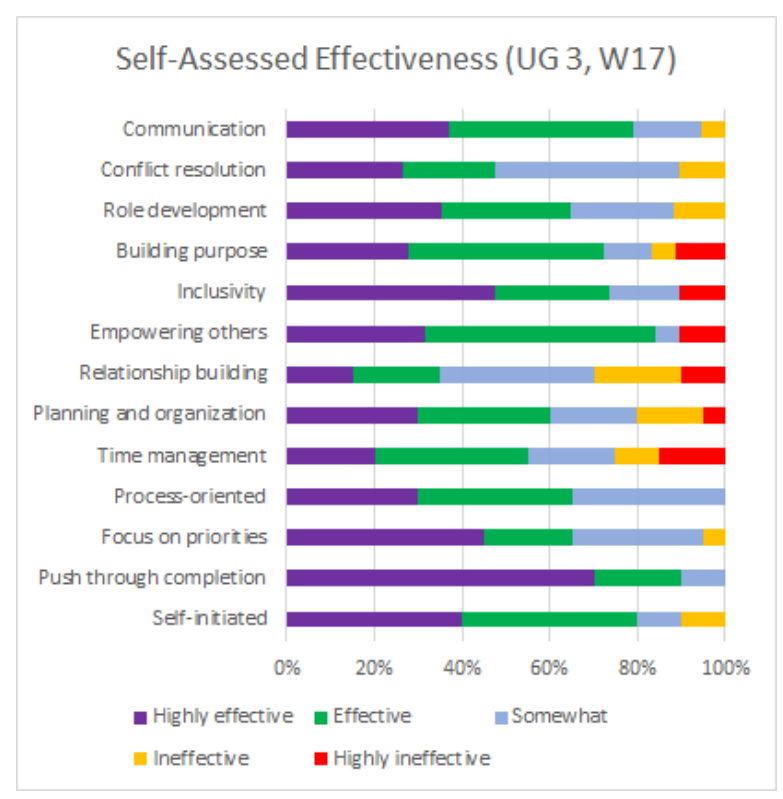

\section{CONCLUSIONS}

Female students recognize and are affected by the way gender norms and preconceptions shape and sometimes create serious challenges to full participate and engage in effective teamwork. Contrary to their female counterparts, male students did not comment on or highlight gendered norms or preconceptions as a part of their engineering education experience. The experience of a gendered environment, can warrant varying levels of disengagement in the education process for female students from feeling unwelcome, not being taken seriously or as competent to their male peer, to the need to work through hostile scenarios in order to address issues of concern and/or gain respect. These issues of disrespect towards the validity of female students in the engineering field not only pervert the design project experience for them but impact the effectiveness with which they engage in their own education

Unchallenged normative practices in engineering education environments that treat female students as 'others' and committed or tacitly approved by any combination of male or female peers, teaching staff and faculty have a direct impact on what is perceived as permissible and unaggressive behavior by male students in the field. Despite the documented and well noted existence of appropriately supportive and inclusive affiliates to the engineering education environment, there is a demand and need for corrective measures of the current inequitable classroom environment. Not only are inclusive language and practices to sensitize instructional staff to meet the needs of marginalized students, they are 
need to actively depress exclusive behavior while avoiding ostracizing of female students as well.

Assumptions about the validity of female perspective, knowledge and ability such as their lack of desire and ability to participate in specific parts of team projects influenced male responses to receiving feedback, identifying issues, and separating the issue from the person.

Both female and male students preferred more inclusive, empowering, purposeful approaches to motivating team members and leading effective teamwork. But the subtle discrimination or disrespect towards female students must be addressed. More research is needed to appropriately identify the impacts and roles of all involved in classroom and design team project setting. Both female and male students were willing to learn and adapt their strategies in working with teams. However, they actively requested more resources and instruction on how to better approach and deal with team dynamics. More research may be useful in this area

We were partly successful in recruiting female participants in the study only after female research staff visited the classrooms. The importance of representation cannot be over-emphasized. More discussion on this is welcome, on how to create a safe space not only in learning but also in research environments.

\section{Acknowledgements}

We would like to thank Dr. Aleksander Czekanski, NSERC/Quanser Chair of Design Engineering, for his enthusiastic support for this study. We also thank the research assistants, Matthew Cheung and Sherif Ibrahim, as well as Julian Bennett for their active contributions to the project.

\section{References}

[1]R. Carrick, A. Czekanski, and M. R. Ha, "Building a more complete design experience: Philosophies and reflections from a second year mechanical engineering design project course," in Proceedings of the 2016 Canadian Engineering Education Association (CEEA16) Conference, 2016, p. Paper 121, 1-8.

[2] K. L. Tonso, "Teams that Work: Campus Culture, Engineering identity, and Social Interactions," J. Eng. Educ., vol. 95, no. 1, pp. 25-37, 2006.

[3] K. L. Tonso, "Student learning and gender," J. Eng. Educ., vol. 85, no. 2, pp. 143-150, 1996.

[4] C. Riegle-Crumb and B. King, "Questioning a White Male Advantage in STEM: Examining Disparities in College Major by Gender and Race/Ethnicity," Educational Researcher, vol. 39, no. 9, pp. 656-664, Dec. 2010.

[5] J. C. Blickenstaff*, "Women and science careers: leaky pipeline or gender filter?," Gender and Education, vol. 17, no. 4 , pp. 369-386, Oct. 2005. 